\title{
AS FORMAS ELEMENTARES DA LIDERANÇA CARISMÁTICA: O VERBO E A IMAGÉTICA NA CIRCULAÇÃO DO CARISMA PENTECOSTAL
}

\author{
Roberta Bivar Carneiro Campos
}

Cleonardo Mauricio Junior

Muito já se escreveu sobre o projeto conversionista das igrejas pentecostais em todo o mundo. Estudos como os realizados por E. Willems (1967), D'Epinay (1970), David Stoll (1982), David Martin (1990), hoje considerados verdadeiros clássicos sobre o assunto, buscavam na privação social e na situação de anomia os fatores que explicariam a conversão e o sucesso da mensagem pentecostal. Muitos destes estudos, em especial aqueles realizados em África, como os de Comaroff \& Comaroff (1991) foram marcados pela situação do encontro colonial. Através de suas análises, os autores sugeriam que, apesar da conversão ao pentecostalismo tratar-se de um tipo evidente de "colonização das consciências", a população local reinventava, à sua maneira, a tradição cristã a ela apresentada, de modo a permanecer culturalmente a mesma. Estes estudos foram marcados ainda pela análise localizada em determinadas áreas geográficas.

Os pesquisadores da atualidade parecem mais ambiciosos num certo sentido, já que desejam explicar a aparente ubiquidade do pentecostalismo. Querem entender o que faz a mensagem cristã - e dentro desta, a pentecostal - viajar bem, sem falar da velocidade com que se replica (Jerkins 2007). Contrapondo-se à tradição que ligava o cristianismo diretamente ao imperialismo, estes autores, de um modo geral, passaram a chamar a atenção para o fato de o pentecostalismo estar sempre sujeito a fraturas, mudanças, sincretismos, dialogismos e mobilidade. Thomas Csordas (2009), por exemplo, propõe, ao invés de afirmarmos simplesmente que a influência cultural da globalização se apresenta na forma unidirecional do imperialismo cultural, reconhecermos que os canais globais estão abertos e que o fluxo de fenômenos religiosos é, no mínimo, bidirecional e, muito provavelmente, multidirecional. Marion Aubrée ${ }^{1}$ também chama a atenção para o fato de a população europeia estar mais receptiva ao pentecostalismo e adverte que 
sua expansão não tem sido somente geográfica, entre os países, mas que há também uma expansão interna, no que diz respeito às relações entre classes sociais, periferia-centro. Aubrée ressalta ainda a importância do alargamento dos elementos culturais através do rádio, da televisão e dos grandes eventos de evangelização como fatores que contribuem grandemente para a expansão do pentecostalismo.

A proposta deste artigo liga-se à questão da diversidade interna no pentecostalismo brasileiro, tendo por intento comparar duas lideranças carismáticas distintas e os modos diversos de propagar a mensagem pentecostal, percebidos entre tais lideranças. Trata-se aqui de Silas Malafaia e Valdemiro Santiago, o "tocador de bombo" e o "comedor de angu": o primeiro, líder da Assembleia de Deus Vitória em Cristo (ADVEC); o outro, líder da Igreja Mundial do Poder de Deus (IMPD). Sendo os referidos termos a maneira como estes líderes se reportam ao início de suas carreiras, quando do relato de suas trajetórias em direção ao topo do que chamamos - esclareceremos mais adiante - de hierarquia carismática. É indispensável afirmar que Valdemiro Santiago e sua igreja servirão aqui como contraponto reflexivo ao modelo de expansão derivado da cultura pentecostal cristalizada nas Assembleias de Deus do pastor Malafaia, construído a partir de trabalho de campo realizado nesta instituição.

Antes de adentrarmos na etnografia desses dois universos pentecostais, faz-se necessário comentar os modelos interpretativos e explicativos do crescimento pentecostal em geral. Analisaremos dois deles, tomando-os como exemplo da contraposição (social x simbólico) existente no panorama dos trabalhos que tentam se debruçar sobre a questão da expansão pentecostal.

\section{Modelo político-institucional}

O modelo da expansão pentecostal apresentado por Ari Pedro Oro (2009) enfatiza o papel das redes religiosas transnacionais na sua análise da circulação religiosa entre os países do Cone Sul. Oro explica que as redes sociais "são organizações compostas de indivíduos ou grupos cuja dinâmica busca a perpetuação, a consolidação e a progressão das atividades de seus membros numa ou várias esferas sociopolíticas" (:228). Devido ao desenvolvimento tecnológico, verificou-se uma potencialização desse modo de ser em sociedade na forma de redes transnacionais. Estas podem ser, de acordo com o grau de institucionalização na qual se configuram (ou buscam se configurar), formais ou informais. Por sua vez, as redes informais também podem se apresentar na sua versão ilícita, na medida em que desenvolvam atividades ilegais. 
As redes religiosas transnacionais observadas no Cone Sul, segundo Oro, seriam semiformais e lícitas, por moverem-se preferencialmente a partir de acordos informais baseados em afinidades ideológicas, alcançando raramente uma institucionalização chancelada pelo Estado, e por agirem dentro da legalidade imposta nas sociedades em que se inserem. A importância de se perceberem os "nós" entre as redes transnacionais também é ressaltada por este autor. Sejam eles agências ou atores, os "nós" detêm as chaves das diversas etapas nas quais os processos transnacionais ocorrem.

As redes transnacionais religiosas também possuem suas instituições ou personagens "nós". Dependendo da ênfase dada às instituições ou às personalidades que as compõem, Oro constrói uma tipologia destas redes religiosas por ele verificadas no Cone Sul. As Redes Transnacionais Institucionais (RTIs) organizam-se tomando como referência as instituições pentecostais (denominações, igrejas etc.). Nelas afirma-se e reforça-se o carisma institucional. Podem ser fechadas ou abertas. As primeiras caracterizam-se pelo exclusivismo, o unidirecionalismo e a centralização. Como exemplos destas redes, Oro cita aquelas formadas pela Igreja Universal do Reino de Deus (IURD) e pela Deus é Amor. Não participam de nenhuma outra rede evangélica nos países em que se instalam, partem sempre do Brasil para outros países e dispensam às igrejas locais um grau de autonomia bastante reduzido. Já as RTIs abertas possuem como principais características o multidirecionalismo, a abertura e o contato com outras redes evangélicas. A Assembleia de Deus (AD) e a Igreja do Evangelho Quadrangular (IEQD) seriam exemplos de tais redes intrainstitucionais em que ocorre certo intercâmbio transnacional entre elas. Movem-se em diferentes direções: do Brasil para o restante do Cone Sul e vice-versa, tanto quanto para outros países. Verifica-se também uma circulação multidiretiva de pastores e fiéis.

As Redes Transnacionais Personalizadas (RTPs) giram em torno dos sujeitos sociais que circulam internacionalmente, seja para participarem de eventos religiosos internacionais enquanto fiéis, seja para atuarem como pregadores. Tais pregadores se afirmam como "nós" ou empreendedores carismáticos. ${ }^{2}$ Por trás de cada um deles há uma instituição, mas o seu carisma pessoal se sobrepõe ao institucional.

\section{Modelo centralizado na expansão simbólica e nas interações rituais}

Se utilizássemos o roteiro malinowiskiano de etnografia, poderíamos afirmar, não antes de reconhecer a importância de seu trabalho para a compreensão 
da esfera social da expansão pentecostal, que o modelo de Oro se encerra no "esqueleto" da pesquisa. Faltaria o "espírito", ou seja, as ideias dos nativos referentes aos fenômenos verificáveis pelo pesquisador. O papel do sistema simbólico e das interações rituais pentecostais alimentadas por esta simbologia não pode ficar de fora de uma tentativa de explicação da expansão pentecostal, entendido aí que o sucesso da mensagem se infere, sobretudo, a partir das adesões e das conversões de fiéis.

Baseado na assertiva de que o objeto da religião é a alteridade e de que diferentes religiões elaboram diferentemente a noção de alteridade, Joel Robbins (2008) afirma que o cristianismo apresenta um caráter radical da alteridade do céu. Existe uma tensão básica entre o transcendente e o mundano. Além de radical, esta tensão é também hierárquica, sendo o transcendente mais valorizado. Isto transforma o cristianismo, principalmente a sua versão pentecostal, segundo Robbins, em um espelho da ordem global. Bom para pensar a ordem global, o cristianismo forneceria um idioma com o qual se pode discutir como é viver longe do centro do mundo. Bom para viver, sugeriria às pessoas formas de conduzirem suas vidas, valorizando-as mesmo em face da situação periférica em que vivem, já que estão a caminho do transcendente. Em suma, a radicalização entre o transcendente e o mundano no pentecostalismo seria crucial no enfrentamento da marginalização que a globalização legou à periferia do sistema mundial. Se sua posição no mundo global relega a periferia à marginalidade, enfatizar a preeminência do transcendente compensa tal situação. A mediação pelo Espírito Santo entre o transcendente e o mundano tornaria a convivência com este hiato um projeto dotado de sentido. Ainda que o céu não seja alcançável antes da vinda do milênio, há bastante de seu poder disponível, aqui e agora na Terra, para tornar a vida um projeto realizável.

As peculiaridades do sistema simbólico pentecostal continuam a ser explicitadas por Robbins (2004) em outro trabalho. A ênfase que o pentecostalismo dá à descontinuidade consiste numa chave importante para explicar a forma como ele se globaliza, a ponto de ser considerado por este autor como uma "cultura contra a cultura". Se todas as religiões conversionistas compartilham esta ênfase na descontinuidade de alguma forma, Robbins sugere quatro maneiras pelas quais esta abordagem seria distinta no pentecostalismo: a religião pentecostal se distinguiria por ritualizar esta descontinuidade cotidianamente; mantendo-a através de um código ascético embebido num profundo dualismo (Deus x diabo) de grande força hermenêutica; além disso, preserva o que, ao mesmo tempo, quebra, na medida em que mantém, mas demoniza a cultura local; providenciando através deste dualismo uma linguagem extremamente sensível às vicissitudes locais. 
Em artigo mais recente sobre o tema, Robbins (2009) busca superar os estudos já intitulados aqui como clássicos, que se baseavam na anomia e nas privações da alta modernidade para explicar a expansão pentecostal. Os próprios trabalhos de Robbins citados anteriormente $(2004,2008)$ ainda guardariam esse ranço funcionalista, o que parece ser superado quando ele ajusta o foco e se debruça sobre as interações rituais presentes no pentecostalismo, derivando daí o que Merton chamaria de uma teoria de médio alcance. Para Robbins, são falhas as abordagens que explicam o sucesso das igrejas pentecostais num contexto em que outras instituições, sejam elas políticas, econômicas ou sociais, têm declinado ou simplesmente sumido, como consequência exclusiva da compensação oferecida por estas igrejas às perdas e às privações sofridas pelas pessoas nas mãos da ordem global.

O verdadeiro motivo do sucesso das igrejas pentecostais é a sua produtividade social, ou seja, sua capacidade de serem bem sucedidas como instituições. Esta "institution-building ability" acontece, por sua vez, devido ao papel fundamental que o ritual ocupa entre os pentecostais. Para explicar como isto acontece, Robbins toma emprestada de Randall Collins a noção de interação ritual. Collins generaliza o conceito durkheimiano de efervescência coletiva e explica que toda interação bem-sucedida produz um tipo de efervescência que ele chama de energia emocional. Ainda mais, todo indivíduo busca interações nas quais possa obter esta energia emocional, mudando de interação em interação até que possa encontrá-la, criando o que Collins chama de uma cadeia de interações rituais que dá forma à sociedade. Robbins, utilizando-se das ideias de Collins, argumenta que o sucesso pentecostal se dá em função de este movimento ser especialista em produzir interações rituais bem-sucedidas, ou seja, fornecedoras de energia emocional (Robbins 2009).

Ainda na trilha dos conceitos de Collins, Robbins explica o que exatamente deve haver na interação para que ela se configure como produtora de energia emocional. São dois os aspectos: primeiro, é necessário haver foco mútuo de atenção, "uma consciência por parte dos participantes de que eles compartilham intersubjetivamente uma definição comum do que estão fazendo juntos" ${ }^{\prime 3}$ (Robbins 2009:61, tradução nossa); segundo, é necessário um alto grau de "emotional entrainment", ${ }^{4}$ ou seja, a noção de que os participantes estão, de forma coordenada, entrando numa corrente emocional. E isso se daria, principalmente, através da sincronia corporal. Robbins acrescenta ainda que o pentecostalismo é especialmente adequado para lançar mão destes dois aspectos da interação ritual bem-sucedida. O conhecimento compartilhado de seus rituais, tais como o louvor, a oração, 
os cânticos e a cura, assegura o foco mútuo de atenção e "uma vez que os pentecostais estejam juntos em uma estrutura de interação, eles estão preparados para gerar 'emotional entrainment' através da sincronia corporal, o segundo constituinte de uma interação ritual bem-sucedida"5 (Robbins 2009:61, tradução nossa).

\section{Integrando os modelos e ajustando o foco}

Se o modelo exposto por Oro enfatiza a esfera social da expansão pentecostal, Robbins reforça o caráter ritual e simbólico desta. Enquanto a primeira etnografia não lança o olhar sobre a dimensão malinowskiana do "espírito", ${ }^{6}$ Robbins não se estende a contento nas dimensões do "esqueleto" e da "carne e sangue" da etnografia da expansão do pentecostalismo. ${ }^{7}$ Nosso objetivo, portanto, é nos inserir nesta lacuna entre os trabalhos anteriormente citados, tentando integrar modelos baseados nos aspectos sociais e simbólico-rituais da expansão pentecostal, contemplando, com isso, o "esqueleto", "a carne e o sangue" e o "espírito" da etnografia da expansão pentecostal.

Campos (2011) dá início a esta tentativa quando destaca, em artigo recente, o modo como as lideranças pentecostais se constituem em "celebridades da fé". Ao investigar como os pastores apreendem, transmitem e compartilham o carisma entre si e com os seus seguidores, ela apresenta um modelo interpretativo no qual o sucesso pentecostal depende da capacidade que o líder tem de fazer o carisma circular, ou seja, pôr-se em movimento, expandindo-se a partir, e para além, do próprio líder carismático. Blanes (2010), em artigo igualmente recente, também apresenta a noção de compartilhamento do carisma. Entretanto, sua ideia é aplicada apenas entre grandes e pequenos líderes, faltando-lhe ainda etnografia mais substantiva sobre os mecanismos deste compartilhamento. A imagem etnográfica do autor restringe-se ao momento no qual Simão Toko ${ }^{8}$ é possuído pelo Espírito Santo, ao mesmo tempo em que a experiência se estende a 12 pessoas dentre seus seguidores, os quais seriam seus apóstolos.

Já no modelo apresentado por Campos (2011a, 2011b), como observado anteriormente, as lideranças se constituem em "celebridades da fé", realizando a performance carismática, transmitindo e compartilhando o carisma entre pequenos líderes e demais seguidores. Para ela, portanto, além de coletivo, o carisma é compartilhado. ${ }^{9}$ Isto significa que não só os grandes líderes, mas também os demais seguidores (sejam eles pequenos líderes ou fiéis e seguidores em geral) podem ser portadores do carisma pentecostal e não apenas partícipes do reconhecimento social do carisma do líder maior. 
É deste compartilhamento que se pode imaginar a circulação do carisma, ou seja, entender como ele é posto em movimento, expandindo-se a partir e para além do líder carismático.

O esforço em integrar abordagens explicativas da expansão pentecostal baseadas tanto nos aspectos sociais quanto simbólicos torna-se mais clara diante da sugestão de Campos de que o carisma circula na forma de três fluxos principais: 1. através de sua comodificação: bíblias comentadas, DVDs, CDs; cursos oferecidos para liderança ou grandes conferências itinerantes de caráter transdenominacional e internacional, como o Breakthrough (Oro 2010), Willow Creek Global Leadership Summit, ESLAVEC etc.; 2. através dos nomes de família: famílias inteiras tornam-se portadoras de carisma, a exemplo da família Malafaia (ADVEC), Soares (Internacional da Graça de Deus), Alencar (AD Bom Retiro) e Valadão (Lagoinha); 3. através de um canal energético emocional e corporal entre pastores e fiéis.

Destaca-se ainda a possibilidade de sobreposições dos fluxos. Bruno Reinhardt (2012), mais recentemente, chamou a atenção para outro canal de circulação de carisma: o do parentesco espiritual. Linhagens de parentesco com líderes religiosos fundamentadas não na aliança e no sangue, mas com base no espírito, podem se formar através da participação de pequenos líderes ou leigos em seminários e cursos de grandes líderes, como também a partir do consumo de produtos midiáticos oferecidos por celebridades da fé. O leigo e/ou a pequena liderança composta por discípulos podem requerer parentesco espiritual com um líder religioso a quem admiram, tomando-o como exemplar, e podem afirmar seguir seus caminhos (ver Reinhardt 2012, mimeo).

Para este artigo, iremos nos debruçar especificamente sobre o terceiro fluxo carismático apontado por Campos (2011a e 2011b). Esperamos, com isso, dar um passo adiante em relação aos trabalhos de Oro e Robbins e consolidar a proposta de preencher a lacuna, já apresentada, percebida entre eles. Desta forma, nosso propósito será construir um modelo heurístico que dê conta, ao mesmo tempo, dos aspectos sociais e simbólicos da expansão pentecostal. Além disso - e esta será a especificidade deste artigo — visamos desvelar os mecanismos desta expansão: se Robbins ajusta o foco e acrescenta à sua macroteoria da expansão do pentecostalismo uma análise mais detida das interações rituais no seio deste movimento, pretendemos aproximar ainda mais o foco e analisar a interação ritual entre o pastor e os seus ouvintes-seguidores nos seus meandros. Isto feito, entendemos que estará solidificada a ideia de uma relação entre (1) a performatividade do carisma e (2) a expansão da mensagem pentecostal ao longo da cadeia de circulação carismática que se forma a partir destas interações. 


\section{O líder carismático: de "nó" e empreendedor carismático a gatilho e emblema}

No modelo construído por Oro (2009), o líder carismático assume o papel de "nó" entre diferentes redes sociais, além de ser considerado um empreendedor carismático, ou seja, protagonista principalmente de eventos, como as chamadas cruzadas evangelísticas, ou dos programas cotidianos veiculados na mídia. Nele, o pastor carismático desempenha um papel político e seu êxito se dá na medida em que detém a "chave", para usar o termo de Oro, que abre o processo de construção e comunicação entre as diversas redes. Robbins (2009) não problematiza diretamente o papel do líder carismático no seu trabalho. O que se vê no seu modelo é a importância da cadeia de interações rituais produtora de energia emocional na expansão do pentecostalismo. Entende-se a energia emocional como fruto de uma interação coletiva, manifesta em uma sincronia corporal entre o pastor e os fiéis.

Dito de outro modo, se a ideia de nó, em nossa leitura do sentido dado por Oro, restringe-se a conexões sociais, as cadeias rituais emocionais em Robbins parecem, por sua vez, desconsiderar, ou pelo menos nelas não se destaca, a importância do líder carismático. É em Émile Durkheim que podemos encontrar contribuição importante para pensarmos o líder tanto como "nó" quanto como desencadeador de fluxos corporais e emocionais, mais precisamente na sua discussão sobre a origem das crenças totêmicas. Aqui estamos seguindo pista oferecida por leituras recentes de interacionistas simbólicos (ver Cossu 2010) sobre a obra deste autor memorável da socioantropologia da religião, as quais contradizem a ideia já comum nas ciências sociais de que a abordagem durkheimiana não contemplaria as práticas sociais, nem tampouco a dimensão processual de criação das representações sociais coletivas. O que importa destacar para o argumento deste artigo é a noção, isto é, o conceito de emblema durkheimiano, no qual entendemos estar contida toda uma noção de caráter processual ou, para usar termo utilizado por Pierre Sanchis (2003), "dinamogênica", já que é na análise dos emblemas sagrados que aquele autor (Durkheim) sinaliza para a produção prática da sacralização do profano.

Ao definir religião como sistema de força, Durkheim argumenta que esta força só se faz eficaz se materializada em coisas, objetos, homens e animais mediante práticas sociais. As representações, portanto, não existem apenas no plano ideacional, mas no material e prático, formatando as ações sociais. Não é muito destacar que o caráter sagrado nesta discussão não é algo que está dado nas propriedades intrínsecas do líder, tendo por referência o carisma como parte do que nele é considerado sagrado, mas 
que lhe é, ao contrário, algo acrescentado, incorporado, atribuído. Em uma só palavra: coletivo. É na ação prática, ademais, e ritualística que as coisas sagradas são produzidas. Na etnografia que se segue poderemos perceber como o líder funciona como emblema na medida em que assume a dimensão material da força sagrada, sendo o líder a força mesma, podendo ser vista, tocada e fundamentalmente imitada. É através do contágio da força sagrada que podemos imaginar, no universo do pentecostalismo, cadeias corporais e emocionais que têm por "nós" os líderes carismáticos. Depreende-se daí que o líder carismático seria o gatilho que dispara este fluxo (Mauricio Junior 2010). A partir de sua performance nos cultos, os fiéis entrariam conjuntamente no ritual produtor de energia emocional. Além de "nó", o líder carismático seria, portanto, especialista em promover interações rituais produtoras de energia emocional.

\section{A busca generalizada pelo carisma e a multiplicação de profetas pelo "batedor de bombo"}

Apesar de Oro ressaltar o caráter ideal-típico de seu modelo e enfatizar que "a etnografia da formação, dinâmica e funcionamentos das principais redes pentecostais transnacionais que vigoram no Cone Sul [...] constitui um trabalho ainda a ser feito" (2009:233), ele afirma que, com a concretização desta, o pesquisador possivelmente encontrará uma relação entre redes mais burocratizadas e contratuais (acordos entre instituições), de um lado, e denominações mais carismáticas e redes mais personalizadas (acordos entre indivíduos), do outro.

No entanto, se verificarmos a rede formada por Silas Malafaia, por exemplo, tomando por base a etnografia realizada por Mauricio Junior (2011), nas igrejas filiais da ADVEC em Recife e no Congresso de Avivamento Despertai (evento protagonizado pelo Ministério do Pr. Malafaia e que se deu na mesma capital, em outubro de 2010), perceberemos um borramento na tipologia proposta por Oro. Pode-se dizer, primeiro, que a rede formada por Malafaia se enquadra no tipo Institucional Aberta. Pertencente à denominação da Assembleia de Deus (AD), os eventos por ele capitaneados, como o Congresso Despertai, conta com a presença de pastores de outros ministérios da $\mathrm{AD}$, bem como de outras denominações. Internacionalmente, Silas Malafaia tem "colado" sua imagem a ícones da chamada Teologia da Prosperidade, como Morris Cerullo, Mike Murdock e Myles Munroe. Por outro lado, suas igrejas-filiais estão submetidas a um restrito grau de autonomia. As decisões, até mesmo no nível da programação semanal, são 
tomadas pela igreja-sede, localizada na cidade do Rio de Janeiro, o que aproximaria esta rede das definidas como institucionais fechadas, seguindo a tipologia de Oro.

Além disso, tratamos a olhos vistos de um dos líderes carismáticos mais preeminentes no cenário pentecostal brasileiro e, sem dúvida, nos termos de Oro, um dos maiores empreendedores carismáticos no panorama pentecostal atual. Sendo assim, a rede formada por Malafaia estaria no meio do caminho entre uma rede institucional e pessoal: mesmo após rachar com o principal órgão nacional das ADs, a Conferência Geral das Assembleias de Deus (CGADB), Malafaia não quis se desvincular do carisma institucional detido pela maior igreja pentecostal do Brasil. No entanto, é o seu carisma pessoal o carro-chefe de sua atuação na esfera pública. Seus eventos são organizados sob a bandeira do seu ministério, a Associação Vitória em Cristo, no qual a interdenominacionalidade é afirmada e a imagem do pastor Malafaia, condutor de vários outros pastores que o reverenciam, supera a instituição que está por trás dele. Nota-se também, na trajetória de Silas Malafaia, sua participação no fluxo carismático com base em alianças e linhagens de parentesco. Ele fez sua carreira na igreja do sogro, quando era apenas um "batedor de bombo" (como veremos mais adiante em um trecho de sua prédica).

Comentado o lugar ocupado por Silas Malafaia nas redes sociais transnacionais, passamos agora para a compreensão deste líder como emblema e gatilho de interações rituais. Apresentar-se como emblema, ou seja, como dissemos anteriormente, assumir a dimensão material do carisma, consiste em se tornar fonte de exemplaridade da fé. É reunir em si mesmo os requisitos pertencentes ao que podemos chamar de cultura pentecostal, entendidos como indispensáveis à atribuição do status de "pessoa cheia do Espírito Santo". Reunidos tais elementos, considera-se que a pessoa possui "autoridade", ou "legalidade", para compartilhar tal força sagrada, estendo-a aos outros, reforçando, com isso, sua própria autoridade. Que elementos são esses? O que significa ser uma pessoa "cheia do Espírito Santo"?

Partindo do trabalho de Campos (2011a e 2011b), a já citada etnografia de Mauricio Junior (2011) acrescenta um ponto importante a esta discussão. Para ele, a principal característica da cultura pentecostal é a busca generalizada pelo carisma. Diante disto, mais do que querer o carisma para si, empreender uma carreira espiritual (e, por conseguinte, a busca pelo carisma necessário para realizá-la) é dever de todo crente pentecostal. Dos fiéis entrevistados, quando perguntados se possuíam uma vocação específica, apenas um, justamente o único evangélico não pentecostal, disse não ter um "chamado" especial. O restante, todos da $\mathrm{AD}$, disseram 
exercer ministérios ${ }_{1}^{10}$ como os da oração, da visita a hospitais, da pregação da palavra e o da "ministração" dos louvores. E para exercer estes ministérios, como dissemos, os crentes devem se "encher do Espírito Santo", ou seja, internalizarem o carisma, sob risco, sem o poder do Espírito Santo, de se encontrarem impossibilitados de realizar os "propósitos de Deus" para eles aqui na Terra. O que os fiéis da AD entendem por estarem "cheios do Espírito Santo" e aptos a desenvolverem suas vocações? Como se dá essa busca generalizada pelo carisma?

Valendo-se dos trabalhos de Simon Coleman $(2000,2006,2009)$ e tendo por foco a liderança de Silas Malafaia, Mauricio Junior (2011) chega à conclusão de que a referida busca se concretiza numa cadeia de circulação verbal, entendida como um processo de internalização e externalização do carisma. Tendo armanezado, internalizado, o carisma em seu self, através das chamadas experiências de in-filling, o fiel precisa estendê-lo (reaching out), ${ }^{11}$ externalizá-lo para o (ainda que desconhecido) outro, sobretudo no ato de "dar uma palavra", "abençoar" ou "profetizar sobre a vida do seu irmão". Um episódio relatado por Nadja, uma das pessoas entrevistadas no trabalho deste autor, ajuda a compreender como se dá esse processo. Internada na véspera de sofrer uma intervenção cirúrgica, Nadja combina de passar este dia "louvando e conversando sobre a palavra" com uma colega crente que havia conhecido anteriormente, na ocasião da conversa com o anestesista, parte dos preparos para a cirurgia. Porém, ao chegar ao hospital levada pelo filho e a esposa dele para ser internada, fica sabendo que não poderia ficar no quarto junto com sua mais nova "irmã". Lamentando, é levada ao quarto onde ficaria para, segundo ela, só depois entender qual seria o "propósito de Deus" nesta ocasião. Ela continua:

Quando eu botei o pé no quarto, eu disse bom dia, quando eu olhei pra senhora que estava deitada, o Espírito Santo de Deus falou ao meu coração: "Ela precisa de você, a outra não. Ela precisa de você". Naquele momento eu comecei a chorar porque foi muito forte. Aí eu já fui pedindo perdão a Deus... Senhor, me perdoe, me desculpe. Eu disse bom dia, eu já fui dando bom dia, eu tava com meu filho e minha nora. - "Quem vai ser minha companheira de quarto?", ela falou bem fraquinho. - Eu disse: "Sou eu". Um dia antes um irmão disse assim: Olhe Nadja, você vai ser usada naquele hospital e, se você não tiver palavras pra dizer, diga só que Jesus é bom. Quando eu entrei que olhei, ela tava com uma imagem [de santo católico] bem grande ao lado da cama e um terço na mão. Eu percebi que ela era bem católica e eu aprendi muito a respeitar. Não sou de agredir porque eu creio que essa obra quem faz é o Espírito Santo. Eu disse: Jesus, como é que eu vou falar pra essa mulher; me lembrei logo da 
palavra do irmão ("diga só que Jesus é bom") . De repente, o meu filho saiu e minha nora, e eu fiquei só com ela e a filha dela. E ela começou a passar mal, uma meia hora depois ela começou a passar mal... Ela tava com uma sonda no nariz. E a filha dela ligando para o [outro] filho dela que vinha e dizendo: "Ela só tá esperando você pra sedar. Ela chamou por você a noite todinha". E ela começou passando mal, passando mal e a filha chamava, chamava na cigarra e o médico não vinha. Aí a filha saiu pra chamar o médico. Saiu correndo pelo corredor e eu fiquei com ela. Na hora o Senhor falou: "Segura na mão dela". E eu segurei. Não tinha nem trocado de roupa ainda, não tinha botado a roupa do hospital. Segurei na mão dela, aí vi o nome dela [na placa acima da cama]. [Então, eu disse:] "D. Maria José, Jesus é bom. Me lembrei [das palavras do irmão] e comecei: "Jesus é bom, Jesus é bom, chame por ele, chame por ele, D. Maria José, que ele está aqui. Vamos chamar por Ele, porque Ele é bom". Aí comecei falando do amor de Deus: "Ele te ama, te ama". E, de repente, ela olhou pra mim e começou a dizer: "Jesus, ela está dizendo que tu és bom. Tu és bom, tu és bom". E a gente começou a glorificar o nome do Senhor. Eu comecei a orar com ela, exaltando só o nome do Senhor. Quando a filha chegou com o médico, ela já estava calma. O médico examinou e foi embora.

Aqui, o ciclo de internalização e externalização do carisma se revela por completo. Nadja primeiro recebe do "irmão" o que deve ser dito no momento oportuno: "Jesus é bom". Armazenada "em seu espírito", a palavra alcança sua eficácia performativa na externalização: o momento em que "pode se dar vida à Palavra, na medida em que a linguagem é externalizada do falante e se transforma num sinal físico da presença do poder sagrado" (Coleman 2000:131, tradução nossa). ${ }^{12}$ É o instante em que Nadja, como diria Coleman (:131), passando a fé aos outros (passing faith on others), segura as mãos de dona Maria José e movimenta o "Jesus é bom", antes recebido, na direção do mais novo recipiente deste interminável ciclo de verbalização da Palavra.

Se a busca pelo carisma não é uma opção ofertada ao crente, sendo compulsória sua adesão a esta corrida, é porque é nela que a identidade pentecostal é construída. Os fiéis, encontrando-se permanentemente submetidos ao escrutínio da comunidade, necessitam provarem-se, e permanecerem se provando, como pessoas "cheias do Espírito Santo". Dominar as situações como a relatada por Nadja, de verbalização do carisma armazenado no self, significa alcançar o reconhecimento como homem ou mulher "cheio do Espírito Santo". Este é o principal indicador do sucesso espiritual dos fiéis. A sanção coletiva da identidade carismática se consolida nos momentos, formais ou não, destinados ao compartilhamento das experiências de cada 
crente: nas cartas lidas nas ocasiões de testemunho, quando se tem a oportunidade de pegar o microfone e "contar suas vitórias" na igreja, ou mesmo, e principalmente, nas conversas cotidianas entre os crentes, como acontece nos "cultos da vitória" realizados às quartas-feiras na ADVEC-Caxangá (Recife-PE), onde fizemos majoritariamente nosso trabalho de campo. Aí o escrutínio toma forma, e o crente pode "prestar contas" de seu carisma, reconhecendo-se, e sendo reconhecido, como pentecostal.

Entendidos os fundamentos da cultura pentecostal, abre-se espaço para compreendermos a existência do líder carismático como consequência dos desdobramentos desta cultura. É dela que eles são emblemas. Se o crente pentecostal precisa trilhar sua carreira espiritual, pode-se deduzir que tal carreira possua um topo. Porém, nem todos o alcançam. É lá que estão os grandes líderes carismáticos, os "santos" protestantes de Coleman (2009): aqueles, em nossos termos, que foram bem sucedidos na busca generalizada pelo carisma, atingindo, pode-se dizer, o sucesso carismático. Se a cultura pentecostal caracteriza-se sobretudo pelo processo incessante no qual os fiéis aderem ao processo de internalização e externalização do carisma, podemos afirmar que o líder carismático se encontra numa posição privilegiada dentro, ou melhor, na origem e acima desta cadeia de circulação (majoritariamente) verbal. O momento em que o crente comum "dá uma palavra" ou "profetiza sobre a vida" de outrem pode ser compreendido como uma reprodução em menor escala do instante da mensagem proferida pelo pastor, ou seja, além de emblema, o líder configura-se aí como o pedagogo do carisma (Seguy 1982).

Podemos afirmar, em resumo, que o líder carismático eleva do nível do prosaico ao do extraordinário as interações sociais das quais se depreende o sentido do carisma entre os pentecostais. Desta posição elevada acima dos seus pares, ele dá início à circulação do carisma, mostrando aos fiéis como este deve ser performado. Vejamos como faz Silas Malafaia em sua prédica no Congresso de Aviamento Despertai. Assim ele a inicia:

Eu quero trazer uma palavra pra você e a minha oração é que eu seja apenas instrumento da vontade de Deus para a sua vida. Eu quero dizer pra você uma coisa que seja profética para sua vida: Deus quer usar você para coisas grandiosas (gritos da plateia de Glória a Deus e Aleluia)...

[...] Então, Ezequiel 37, versículo um [diz]: (lendo) "Veio sobre mim a mão do Senhor, e o Senhor me levou em espírito e me pôs no meio de um vale que estava cheio de ossos". Há duas coisas aqui que eu quero considerar deste primeiro versículo: É que Deus sempre vai nos levar ao lugar [em] que ele quer nos usar. Então aprenda o seguinte: É Deus que tá dirigindo a tua vida? Sim ou não? (plateia responde, sim). Se for Deus que está dirigindo a tua vida, não 
fique preocupado com o aparente e com as circunstâncias. Deus sempre vai te levar a um lugar, e te prepare, nesse lugar você vai ser usado para a glória d'Ele (gritos da plateia de "Glória a Deus" e "Aleluia")...

[...] Te prepare, porque o lugar que Deus te levar (aumentando o tom de voz) é lugar de VI-TÓ-RI-A (gritos da plateia de "Glória a Deus" e "Aleluia")...

Malafaia posiciona-se como um interlocutor privilegiado de Deus, apto a entregar aos seus ouvintes uma mensagem eficaz ("Eu quero dizer pra você uma coisa que seja profética") e de resultados incomuns, grandiosos ("Deus quer usar você para coisas grandiosas", "neste lugar você vai ser usado para a glória dele"). O conteúdo desta profecia nos auxilia a ratificar o entendimento de que o fiel quer o carisma para si. Ele, o fiel, deseja fortemente "ser usado por Deus" e realizar em sua vida o comissionamento dispensado pelo seu líder. Esta é a condição para entender-se, e ser entendido, como pentecostal. Para tanto, o crente deve ser "cheio de poder". Podemos perceber esses momentos (para os fiéis, literalmente) como de "recebimento" destas palavras: com o fiel balançando a cabeça em sinal de afirmação, braços estendidos em direção ao palco, com as palmas das mãos voltadas para cima (em posição de recebimento), tudo isto acompanhado por gritos sincronizados (as pessoas sabem os momentos corretos de utilizálos) de "Glória a Deus" e "Aleluia", que funcionam como uma resposta, uma aceitação da palavra proferida pelo pastor.

Configura-se, portanto, nos dizeres de Coleman, "uma construção especificamente carismática do sentido de um fluxo entre o santo [o líder carismático] e o crente comum..." (Coleman 2009:430, tradução nossa). ${ }^{13}$ E é sobretudo nesse instante da mensagem que pastor e fiel se engajam numa interação na qual se constrói a percepção desse fluxo, partindo do primeiro e sendo recebido pelo segundo. Nesse momento, o sagrado se expande contagiosamente entre os presentes.

Vê-se que Malafaia cumpre o dever de estender-se até o outro (reaching out), entregando-lhe a Palavra como todo crente deve fazer, no entanto, o faz em outro patamar, bem mais elevado. Enquanto o crente ordinário executa o que a comunidade considera ser sua missão, engajando-se em interações com pessoas que estejam ao alcance de suas mãos, por exemplo, com uma companheira de quarto de hospital, conforme o depoimento de Nadja aqui relatado, o pastor-celebridade o faz, por sua vez, diante de uma plateia ávida por aprender com ele, e no momento considerado como a principal oportunidade para se "receber", internalizar, a Palavra. Eliete, outra entre os entrevistados, nos diz que momento é este: "O momento principal do culto?... é o momento da palavra. É muito bom o momento de adoração... 
Mas aqueles hinos são como uma preparação para ouvir a palavra. Mas na hora da palavra é a hora que você vai aprender". Além disso, o "grande homem de Deus" não se limita às paredes da igreja local. É visto nos eventos itinerantes de alcance nacional e internacional, e alcança todos com sua mensagem através do rádio e da televisão.

Esta hierarquia carismática, ${ }_{1}^{14}$ porém, encontra-se subjacente à cultura pentecostal de forma tácita. Não pode ser desnudada ou verbalizada pelos profetas, pois o que se busca entre os pentecostais é uma conexão direta com o Espírito Santo. Abertamente, não se admitem intermediários ou crentes mais santos do que os outros. Assim, para manter sua autoridade acima de pastores e crentes comuns, o líder carismático precisa atuar constantemente no que Csordas (1997) chama de semiotic gap (lacuna semiótica), caminhando sobre a ambiguidade nas suas prédicas e performances em geral. Ao mesmo tempo em que o pastor chega a indexar a sua própria autoridade, deve deixar claro, pelo menos no que diz respeito às declarações públicas, que "o poder vem sempre de Deus". Para entender como a ambiguidade é performatizada em meio ao carisma, ou melhor, como é dele parte constitutiva, continuemos com a mensagem do pastor Silas Malafaia no Congresso Despertai. Sua prédica é realizada a partir do texto bíblico encontrado no livro de Ezequiel e apresenta uma metáfora em que o "vale de ossos secos", cenário no qual se passa a trama bíblica que serve de base para sua pregação, representa o início da carreira espiritual de todo crente, onde se realizam feitos considerados menores na hierarquia carismática:

[...] Agora deixa eu falar uma coisa aqui, rapaz, que eu tô com vontade de falar porque aqui tem um monte de pastor. E aqui também tem muita gente nova. Deus levou Ezequiel pra onde, hein? [ plateia responde, "para um vale de ossos secos"] Pra um vale o quê? [plateia responde, "de ossos secos"; Malafaia corrige:] Sequíssimos. Você pensa que você vai começar na montanha, meu filho? Tem um vale de ossos sequíssimos te esperando. As pessoas pensam que vão começar por cima, sabe. Entrou no ônibus agora e quer sentar no primeiro banco e na janela. Ahn? Você entrou no ônibus agora? Vai ficar pendurado lá na porta quase caindo. É o lugarzinho que tem pra você, meu filho. O camarada chega agora... [dramatizando:] "Não, porque eu vou... eu vou ter uma igreja de tanto". [Dá uma gargalhada em tom de chacota:] Deixa eu rir de você. Meu filho, primeiro tem um vale antes de Deus te colocar no topo da montanha. Você vai ter que passar pelo vale [E, aumentando o tom de voz] Não reclame, não! Deus está te preparando no vale pra te levar aos lugares altos desta vida ou do ministério [gritos de "Glória" e "Aleluia"]... pra chegar no topo passa pelo vale [mais gritos de "Glória" e "Aleluia"]. 
Aqui, Silas Malafaia profetiza "do alto da montanha" e deixa claro que antes de alguém alcançar o lugar onde será "usado poderosamente", antes de se estabelecer, como ele, "no topo da montanha", é necessário "passar pelo vale de ossos secos", como também aconteceu com Ezequiel. Subentendese que, se Silas Malafaia dá as diretrizes para que se possa deixar o "vale" e chegar ao topo, ele já trilhou este caminho. Assim sendo, ele apresenta o tempo em que ainda estava no "vale":

Sabe como é que eu comecei na igreja? Batendo bombo. Comecei batendo bombo. E meu sogro gostava de fazer todo domingo um desfile... Meu sogro gostava de fazer um desfile da Praça da Penha à Praça São Lucas... Um quilômetro, um quilômetro e meio, sabe. A banda na frente, a igreja atrás e ele na frente da banda com a Bíblia. Três horas da tarde de domingo. Era uma coisa linda. E pra azar meu, quando não tinha hino, quem batia a marcha era o bombo. E quem era o besta que tava lá? [imitando o som do bombo e gesticulando como se estivesse tocando] Bum, bum, bum. Não tinha música nenhuma, mas o bombo funcionava [risos]. Cansei de bater bombo, rapaz. Você tá pensando que eu comecei o quê, por cima? Cansei de pregar de madrugada na zona sul do Rio de Janeiro com meus colegas da igreja. Cansei de pregar dentro de ônibus, distribuindo folheto dentro de ônibus, meu irmão. Cansei de fazer isso... Mas rapaz, a gente começa em baixo. Ninguém começa pregando pra televisão, não. Ei [aumentando consideravelmente o tom de voz], tem um vale de ossos secos pra você se preparar. Mas eu sou profeta de Deus [gritando]. Deus também tem uma montanha pra você subir e conquistar [gritos].

A carreira espiritual que o crente deve trilhar e a hierarquia carismática que dela decorre vêm à tona nas palavras de Malafaia. Se um dia ele se limitava a bater bombo à frente do séquito comandado pelo seu falecido sogro, líder anterior da ADVEC, Malafaia agora prega do alto de um palco, sua "montanha", numa casa de shows lotada com transmissão para dezenas de países. Ele não pode, porém, se esquecer de dar o devido crédito a Deus pelo seu sucesso:

Agora olha o que é que diz o versículo 5: [lendo] "Assim diz o Senhor Jeová a estes ossos: ‘Eis que farei entrar em vós o Espírito e vivereis'. Versículo 6: 'E farei nervos sobre vós e farei crescer carne sobre vós. E sobre vós estenderei pele e porei em vós o Espírito e vivereis. E sabereis que Eu sou o Senhor'". Ezequiel quer operar tudo aquilo através de quem? [plateia responde] — de Deus. Não esquece isso não, meu filho. Porque enquanto é osso sequíssimo não dá pra ficar metido a besta, mas quando é um grande exército [dá uma risada]: Ai meu 
Deus... Ei, ei, o tempo todo, o que vai ser feito é o Senhor que vai fazer através de você. Não fica metido a besta, não, que papai do céu puxa o tapete... É a mão de Deus, é o favor de Deus, é o agir de Deus [aumentando o tom de voz]: É a misericórdia de Deus, é a bondade de Deus o que somos, o que temos, o que fazemos. É Deus, é Deus [num tom de voz ainda mais alto]: A Ele a glória, a Ele a honra, a Ele o louvor para sempre [gritos da plateia]. Não se esquece, não, hein [a plateia irrompe em palmas].

Nesse caminho, de "batedor de bombo" até a conquista "do alto da montanha", sem esquecer, no entanto, de dar a devida "glória a Deus", caminhando, portanto, sobre a ambiguidade, Malafaia constrói sua posição mediadora de uma maneira aceitável pela cultura pentecostal. E ao reunir autoridade para profetizar para os seus ouvintes, Malafaia passa à fase de confirmação da circulação do carisma, afirmando a possibilidade de Deus fazer com que seus ouvintes, crentes comuns, alcancem também o sucesso na busca generalizada pelo carisma ("Deus tem uma montanha para você subir e conquistar"). E os fiéis devem começar já, no contexto no qual se encontram. Malafaia os instiga a isto:

[...] O versículo 4 tem uma coisa interessante: [lendo] "Então lhe disse: Profetiza sobre estes ossos e dize-lhes, Ossos secos, ouvi a palavra do Senhor". Meu irmão, olha que coisa interessante: Quem é que tava com o profeta no vale? Quem? [a plateia responde: "Deus"] E Deus manda o profeta? Aqui tem um princípio: Deus realiza a sua obra aqui na Terra através dos seus servos... Deus realiza aqui na Terra os seus intentos através de você [e apontando aleatoriamente para pessoas da plateia]: De você, de você, é de você. Dá pra vocês dizerem pra dois, três aí, olha: "É através de você. Através de você" [gritos]. É você o instrumento. Tem gente muito enganada... Você é o instrumento de Deus, rapaz. É você. Não é outro, não.

Torna-se mais claro aqui um dos motivos pelos quais o pentecostalismo tem encontrado uma expansão assustadora: o fato de que a construção da autoridade do líder carismático passa pela sua habilidade em motivar seus ouvintes a serem profetas onde estiverem. É isto o que faz Silas Malafaia: exorta os fiéis a cumprirem seus deveres de profetas. Ressaltar o comissionamento por Malafaia de seus profetas, ou seja, o envio dos crentes ordinários em busca de interações rituais que consistam na mímesis da interação-origem (a conduzida pelo próprio Malafaia), possibilita entendermos também como a expansão pentecostal, baseada majoritariamente na multiplicação de profetas menores rumo às suas próprias "montanhas", eleva alguns pastores ao estrelato. 


\section{Uma pedra no meio do caminho: "o comedor de angu"}

Ao tomarmos em perspectiva a etnografia do fluxo carismático no contexto da AD e da liderança de Silas Malafaia, anteriormente comentada, e adiante com a IMPD e a liderança de Valdemiro Santiago, logo nos deparamos com alguns contrastes a serem pensados dentro do modelo analítico exposto anteriormente, isto é, do pastor como nó entre redes sociais e "gatilho" de fluxos rituais emocionais. Esperamos, através do caso de Valdemiro Santiago e de sua igreja, a IMPD, refletir sobre como a propagação da mensagem pentecostal pode se dar de diferentes maneiras, através de distintos estilos carismáticos e com dilemas também diversos. Antes de conclusões contundentes e assertivas, sugerimos alguns questionamentos.

A IMPD classifica-se dentro do segmento que Mariano (2005) chama de a terceira onda do pentecostalismo, ou neopentecostalismo. São facilmente visíveis nos cultos da IMPD as características que definem esta terceira etapa histórica do pentecostalismo inaugurada pela IURD. São elas: um massivo apelo à teologia da prosperidade e a exacerbação da crença na guerra cósmica entre Deus e o diabo, bem como a existência de consequências diretas deste embate na vida das pessoas, como, por exemplo, a possessão. A IMPD possui, segundo seu website oficial, mais de 1.400 igrejas espalhadas por todo o mundo. Estes números foram alcançados desde 1997 apenas, evidenciando um crescimento meteórico.

Foi nessa época que o seu líder maior, o Apóstolo Valdemiro Santiago, desligou-se da IURD após 18 anos e inaugurou o primeiro templo da IMPD no bairro do Brás, em São Paulo, o que agora é sua sede mundial, conhecida como o "Grande Templo dos Milagres". A inauguração da Cidade Mundial em Guarulhos-SP, complexo incluindo templo com capacidade para $150 \mathrm{mil}$ fiéis, no primeiro dia de 2012, repercutiu na mídia pelo enorme fluxo de pessoas para o local. Outro complexo do mesmo tipo já possui inauguração agendada no Rio de Janeiro. A IMPD adquiriu, ainda, a concessão da Rede 21, afiliada da Rede Bandeirantes de Televisão no estado de São Paulo, para veicular programação religiosa 24 horas por dia, o que se configurou como o primeiro acontecimento do gênero na TV aberta. Seus programas também são veiculados nas tardes da Rede TV e nas madrugadas da Rede Bandeirantes, multiplicando a exposição desta instituição na mídia.

A rede formada pela igreja de Valdemiro pode ser caracterizada, dentro do modelo de Oro, como do tipo fechada. Porém, não se pode dizer que tal rede se configure nos moldes do tipo institucional, haja vista tratar-se de uma liderança carismática fundada no carisma pessoal do fundador, a ponto de a IMPD e a pessoa de Valdemiro Santiago se confundirem. Por outro lado, o 
carisma de Valdemiro expande-se também através do aparato institucional assentado na IMPD, o que nos leva a entender que a divisão proposta por Oro entre redes institucionais e personalizadas para o âmbito do Cone Sul, dominado, como ele mesmo diz, pelos pastores argentinos, não se adequaria às redes protagonizadas pelos líderes carismáticos brasileiros.

Se Silas Malafaia é reverenciado pela qualidade e o poder de suas pregações, o carisma de Santiago advém das curas por ele efetuadas em seus cultos. Ao contrário do psicólogo Malafaia, Valdemiro enfatiza sua simplicidade advinda de seu passado de homem da roça. Nas suas palavras, continua sendo um simples "comedor de angu". Mas ao mesmo tempo em que rememora seu passado humilde, ressalta seu status de filho privilegiado de Deus ao relatar em um de seus livros, O grande livramento, a ocasião na qual, ainda como pastor da IURD, foi salvo por dois anjos de um naufrágio na África, onde realizava trabalhos missionários, sendo a partir daí que, segundo ele, recebeu o comissionamento para tocar a sua obra através da IMPD. Ter seu rosto estampado na capa da revista Isto É (n²151, fev/2011) e ter o evento carro-chefe de sua igreja, a "Grande Concentração de Milagres" - especificamente a realizada no primeiro dia de 2011 no autódromo de Interlagos - repercutido pela Rede Globo (como também a concentração do ano seguinte, por ocasião da inauguração do complexo da Cidade Mundial) confirmaram Valdemiro Santiago como um dos principais líderes carismáticos brasileiros.

Nem Valdemiro, nem sua igreja, ao contrário de Malafaia, parecem buscar ou estabelecer conexões com outras igrejas ou líderes carismáticos. Observa-se ainda no estilo de pregação de Valdemiro Santiago, em contraste com Silas Malafaia, menor destaque para a palavra lida e repetida, memorizada. Nota-se nos cultos da IMPD mais corpo que verbo. Destacam-se nos cultos os rituais de cura, além de uma profusão de testemunhos que relatam a libertação de todo mal. Ora, o pentecostalismo tem sido descrito por muitos como a religião da palavra (Harding 2000; Crapanzano 2000; Coleman 2000, 2006; Keanne 1993; Engelke 2007) dada a sua importância para a identidade pentecostal e seu lugar, suposto, nos diversos modos de existência do pentecostalismo. Por outro lado, os autores, de um modo geral, chamam a atenção para o fato de o pentecostalismo estar sempre sujeito a sincretismos e dialogismos. Nisto podemos imaginar que o lugar da palavra e as maneiras com que esta se presentifica nos cultos pentecostais também possam sofrer variação. Há, portanto, que se considerar a existência de outros modelos de textualidade e de presentificação da palavra (Keanne 1993; Barber 2007).

Encontramos na análise de Roberto Motta (1991) sobre a possessão no campo religioso afro-pernambucano insight teórico classificatório para 
efeitos comparativos entre as duas denominações em tela. Motta percebe que haveria entre essas religiões dois tipos de transe. Sugere, inspirado em Victor Turner, as categorias transe iconofílico e transe logofílico para designar estas duas espécies de possessão. Com cada tradição afro-pernambucana pode ser identificado um tipo de transe que lhe é mais característico. O que se destaca na análise de Motta, para o interesse deste artigo, é que, dentro do universo afro-pernambucano, é possível identificar religiões em que a palavra tem lugar diferenciado e de destaque, podendo-se assim chamá-las logofílicas; e outras em que a palavra estaria subsumida ao corpo, às imagens. Seriam estas as religiões de tipo iconofílicas, nas quais o conhecimento religioso seria transmitido e realizado através de experiências supradiscursivas, sendo a imagética sua principal maneira de ser. Por exemplo, o xangô seria iconofílico e a umbanda, logofílica.

Num empreendimento análogo, ao estendermos as categorias de Motta para o pentecostalismo, logo podemos identificar as denominações pentecostais que seriam mais logofílicas, exemplificadas aí pela $\mathrm{AD}$, e aquelas mais iconofílicas, como a IMPD. Sugerimos ainda a possibilidade de tipos híbridos, mas não é este o caso para nos determos aqui. Interessante ainda notar que, aplicadas as mesmas categorias a ambos os campos religiosos, percebemos que as estruturas de prestígio e de poder de cada um dos campos formam imagens invertidas entre si. Se no campo afro-pernambucano, pelo menos até bem pouco tempo, é o xangô, uma religião iconofílica por excelência, a que tem maior prestígio, no campo pentecostal, é a AD, religião logofílica, que detém o lugar equivalente àquele ocupado pela referida religião afro-pernambucana. Ao contrário do que alguns possam imaginar, entendemos ser a análise anterior elemento que certamente corrobora com o fato de a palavra ser fundamental à identidade pentecostal, visto ser ela fonte de poder e de prestígio no referido campo religioso.

Mas algumas perguntas emergem: se no sistema religioso logofílico, como vimos na etnografia de Mauricio Junior, o compartilhamento do carisma se dá através de uma cadeia de circulação verbal, como isto se daria numa religião marcada pela iconofilia? Como o contágio do sagrado pelo emblema se daria? Em que termos o gatilho desencadeador do fluxo carismático aconteceria neste contexto? Como e o que os fiéis mimetizariam a fim de se engajarem no fluxo de compartilhamento do carisma para levar a mensagem pentecostal adiante? Mais: este fluxo existe num contexto que parece, à primeira vista, concentrar toda a sua dinâmica expansionista no líder da instituição?

O carisma de Valdemiro encontra na performance, sobretudo da cura, seus momentos de maior efervescência. Parece estar, assim, encurralado em 
seu emblema maior, o próprio Valdemiro. Na AD configura-se, como vimos, uma busca generalizada pelo carisma, que circula impulsionado pelo alto poder de contágio da Palavra verbalizada, passada adiante por grandes líderes, pequenos líderes, fiéis comuns e demais seguidores. Aqui todos são "soldados de Cristo" impulsionados a pregar, a passar a palavra, a exercer o seu carisma, o seu ministério, enquanto na IMPD, não obstante todo o frenesi coletivo e compartilhado, o carisma parece ter circulação mais restrita, já que os dons de cura aparentam circular apenas entre o grande líder e os pequenos líderes (conforme os modelos de Oro e Blanes, já explicitados). Seriam, então, os fiéis de Valdemiro impulsionados a replicar esta cadeia além das fronteiras do culto presencial com o líder nos moldes dos seguidores de Silas Malafaia? Como fariam isso? São perguntas para as quais não temos dados suficientes para responder.

O que faremos, tomando como base as dinâmicas carismáticas verificadas nas instituições pentecostais sobre as quais por ora nos debruçamos, é propor uma tipologia do compartilhamento do carisma. A relação aqui estabelecida se dá entre o compartilhamento generalizado do carisma e o sistema religioso logofílico cristalizado na dinâmica da $\mathrm{AD}$, por um lado; e o compartilhamento restrito do carisma e o sistema religioso iconofílico, por outro lado - falamos agora da IMPD e do carisma da cura de Valdemiro Santiago (ver Tabela 1 abaixo).

\section{Tabela 1}

\begin{tabular}{c|c|c|c|c}
\hline Instituição & $\begin{array}{c}\text { Modalidade } \\
\text { doSistema } \\
\text { Religioso }\end{array}$ & $\begin{array}{c}\text { Abrangência do } \\
\text { Compartilhamento } \\
\text { do Carisma }\end{array}$ & $\begin{array}{c}\text { Principal } \\
\text { Elemento } \\
\text { Carismático }\end{array}$ & $\begin{array}{c}\text { Líder } \\
\text { Carismático }\end{array}$ \\
\hline AD & Logofílico & Generalizado & Palavra & $\begin{array}{c}\text { Silas } \\
\text { Malafaia }\end{array}$ \\
\hline IMPD & Iconofílico & Restrito & Cura & $\begin{array}{c}\text { Valdemiro } \\
\text { Santiago }\end{array}$ \\
\hline
\end{tabular}

Não estamos afirmando com isto que o logos está ausente dos cultos da IMPD, dentro, portanto, do que estamos propondo chamar de sistema religioso iconofílico. Já mencionamos as diferentes formas da presentificação da Palavra (Keanne 1993; Barber 2007) entre os pentecostais. Basta lembrarmos que uma das práticas centrais nos cultos da IMPD, como já mencionamos, é a profusão de relatos e testemunhos de cura. Este fato não foge à nossa 
observação. O que apresentamos aqui são conceitos relacionais, no sentido empregado por Becker (2007): "todos os termos que descrevem pessoas são relacionais - isto é, só têm sentido quando considerados como parte de um sistema de termos" (:173). Em outras palavras, os conceitos aqui utilizados dependem de quem está em comparação. Se os localizarmos no sistema mais amplo de termos e relações referentes às modalidades de performance pentecostal, como nos recomenda mais uma vez Becker (:184) ${ }_{1}^{15}$ a mensagem de Valdomiro, por exemplo, poderia ser classificada como logofílica em relação a outros elementos do sistema. ${ }^{16}$ Mais ainda, se o sistema de referência for o Protestantismo em geral, ambos, Malafaia e Valdemiro, serão considerados iconofílicos em relação às igrejas mais tradicionais. Enfim, enfatizamos nesta tipologia, mais uma vez, uma predominância relacional, e não um traço definido em si mesmo, de práticas e representações.

Em segundo lugar, queremos enfocar a relação destas práticas com o compartilhamento do carisma, a abrangência da circulação de carisma que elas geram: se o carisma centralizado na palavra, nos cultos da $A D$, gera um compartilhamento generalizado através da mímesis baseada na circulação do logos, não percebemos o mesmo acontecendo nos cultos da IMPD. A interação líder carismático-fiel nos testemunhos realizados nesta igreja reiteram somente, no nosso entendimento, o carisma do líder e não promovem o empoderamento carismático dos fiéis "abençoados" com a cura. Percebemos ainda, nos grandes eventos capitaneados por Valdemiro Santiago, apenas os obreiros mimetizando as orações e as técnicas corporais que invocam a cura, ${ }^{17}$ não se dando o mesmo entre os fiéis comuns, o que nos leva a relacionar o sistema iconofílico com um compartilhamento restrito do carisma, em contraposição à cadeia de circulação verbal que se forma tendo a interação líder carismático-fiel como centro irradiador nos cultos da AD.

\section{Considerações finais}

O caminho até aqui percorrido, no intuito de entendermos os diferentes modos da expansão do pentecostalismo, teve sempre em vista construir um modelo que não eliminasse a faceta social, nem a simbólica, desta expansão. Entendemos que a modalidade abordada especificamente neste trabalho, a expansão da mensagem pentecostal, expõe estas facetas citadas. A relação da expansão da mensagem pentecostal com a performatividade do carisma (concretizada através da "multiplicação de profetas" decorrente do seu compartilhamento) revela, ainda, o papel primordial do líder carismático nesse processo (emblema da cultura pentecostal, gatilho e pedagogo das 
interações rituais construtoras do sentido de aquisição do carisma). Silas Malafaia obtém sucesso como celebridade pentecostal na medida em que coloca seu carisma em circulação, propagando-o para além de si mesmo. Parece haver aí uma maior democratização do carisma no sistema religioso logofílico (compartilhamento generalizado do carisma), com o fiel sendo empoderado ao longo da cadeia de circulação verbal, ainda que a hierarquia carismática seja mantida.

Por outro lado, imaginamos o carisma de Valdemiro Santiago, performado no que chamamos de um sistema religioso iconofílico, guardar um segredo (compartilhamento restrito) - sem esquecer, nunca é demais dizer, do caráter relacional destes conceitos (iconofilia e logofilia). Alguém pode insistir ainda ser a palavra tanto ou mais secreta que o dom da cura se ao fiel falta a capacidade de ler. Mas, neste caso, a ele sempre é possível memorizar a Palavra e repeti-la. Portanto, entendemos que o carisma em Valdemiro apresenta-se como menos democrático que aquele fundado na palavra, pois seu acesso e imitação são limitados, envolvido que está em segredo sagrado.

Recebido em 28 de agosto de 2012

Aprovado em 23 de julho de 2013

Roberta Bivar Carneiro Campos é professora adjunta da Universidade Federal de Pernambuco. E-mail: <robertabivar@gmail.com>.

Cleonardo Mauricio Junior é mestrando do Programa de Pós-Graduação em Antropologia da Universidade Federal de Pernambuco. E-mail: <cleonardobarros@gmail.com>.

\section{Notas}

${ }^{1}$ Comunicação proferida no ciclo de palestras sobre "Crenças no Mundo Globalizado", realizado na Fundação Joaquim Nabuco - PE, de 08 a 10 de agosto de 2011.

${ }^{2}$ Como empreendedores carismáticos, Oro considera os pastores que desenvolvem iniciativas pastorais ou midiáticas de grande porte. 
3 "A sense on the part of participants that they intersubjectively share a common definition of what they are doing together."

4 "Entrainment" pode ser traduzido como "embarque em trem" ou "carreamento". Na falta de um termo em português que reúna o sentido desta ação de embarcar num "trem" de emoções, mantenho o termo em inglês (Robbins 2009:61).

5 "Once pentecostals are in a interational frame together, they are well prepared to generate emotional entraiment through bodily sincronization, the second constituent of a successfull interaction ritual" (Robbins 2009:61).

${ }^{6}$ Oro (2010) dá espaço, em outro trabalho, a um entendimento da expansão pentecostal a partir do seu sistema simbólico. Aqui, o carisma do líder se configura como elemento que atrairia os fiéis aos grandes eventos, como o Breakthrough. Esta percepção da exclusividade da posse do carisma pelo líder precisa ser complementada, porém. É o que faremos mais adiante.

${ }^{7}$ Robbins (2004) cita a importância da organização social em redes para a expansão pentecostal. Na trilha de Randal Collins, há uma tentativa de unificar as abordagens eminentemente sociais e simbólicas da expansão pentecostal. Porém, na construção do seu modelo é nítida a ênfase nas esferas simbólica e das interações rituais.

${ }^{8}$ Simão Toko foi o fundador da Igreja Tokoista - movimento profético e reformista de origem angolana e background protestante.

${ }^{9}$ Csordas (1997) constrói um modelo teórico para enfatizar o caráter coletivo do carisma no intuito de se afastar do conceito clássico weberiano, o qual define esta categoria como uma qualidade pessoal extracotidiana atribuída ao líder. O que Csordas enfatiza, no entanto, é que a reiteração da liderança passa pelo reconhecimento dos fiéis. Não explora a ideia de compartilhamento presente em Blanes (2010) e Campos (2011a, 2011b).

${ }^{10}$ Ministério é o termo nativo para vocação, carreira espiritual.

${ }^{11}$ Traduzimos por "estender-se" o termo "reaching out", usado por Coleman (2000, 2006, 2009). Significa um princípio formador da identidade do crente, que deve se estender até, ou alcançar, os outros, contribuindo para a formação de seus selves carismáticos.

12 "The Word can be made to 'live' as signs of language are externalised from the speaker and turned into physical signs of the presence of sacred Power" (Coleman 2000:131).

13 "A specifically charismatic construction of the sense of flow between saint and ordinary believer..." (Coleman 2009:430). 
${ }^{14}$ Entendemos que os fiéis reconhecem, tanto em crentes comuns quanto em pastores e líderes, mais ou menos carisma, o que formaria uma hierarquia carismática, ou seja, baseada no carisma atribuído ao pastor, a outros líderes e até aos crentes comuns. O pastor-celebridade estaria no topo desta hierarquia, que começaria com o crente comum, e passaria por líderes "menores", como cantores gospel, diáconos, evangelistas, líderes de grupos de jovens, de oração nas casas etc. Como veremos mais adiante, esta hierarquia é tácita, já que "a unção do Espírito" está disponível a todos. Este paradoxo leva o líder carismático a atuar sobre a ambiguidade para, mesmo compartilhando carisma, sair destas interações mantendo sua posição acima de outros líderes e dos crentes comuns. Disto decorre (a existência dessa hierarquia) que o compartilhamento do carisma é desigual. Reconhecemos ainda que outros fatores, políticos e sobretudo econômicos, por exemplo, contribuem para posicionar o líder carismático nesta disposição hierárquica. Enfatizaremos, no entanto, como as interações simbólicas, baseadas no "poder do Espírito Santo", contribuem para a definição destas posições.

15 "O truque neste caso é situar qualquer termo que pareça descrever um traço de uma pessoa ou grupo no contexto do sistema de relações a que pertence. Isto nos mostra que o traço não é apenas o 'fato físico', ou seja o que for, mas sim uma interpretação desse fato, uma atribuição de significado a ele, que depende das outras coisas a que esteja ligado. A primeira coisa a que ele está ligado são outros traços, aos quais foram igualmente atribuídos significados, de modo que eles constituem um sistema de possibilidades" (Becker 2007:174, grifo nosso).

${ }^{16}$ Tal classificação não seria, de forma alguma, absurda. Em uma incursão ao campo, na ocasião da Grande Concentração de Milagres realizada por Valdemiro Santiago em Recife (junho de 2011), presenciamos o Apóstolo repreendendo severamente os fiéis presentes, porque estes, depois do momento separado para a realização das curas, não estavam fazendo o silêncio que o pregador, o próprio Valdemiro, entendia ser necessário durante o momento da prédica, fato que o "entristecia muito". Também não é demais dizer que, tanto em seus eventos quanto nos programas de televisão, recorre-se sempre à imagem, transmitida no telão, de uma Bíblia na qual alguém aponta o versículo bíblico a que se está fazendo referência.

${ }^{17}$ A oração, em tom de comando, com as mãos impostas sobre o indivíduo, ou tocando diretamente no local da enfermidade, seguida de gritos de "Sai!". 


\section{Referências bibliográficas}

BARBER, K. 2007. The anthropology of texts, persons and publics. Oral and written culture in Africa and beyond. Oxford: Oxford University Press.

BECKER, Howard S. 2007. "Conceitos são relacionais". In: Segredos e truques da pesquisa. Rio de Janeiro: Zahar. pp. 172-179.

BLANES, Ruy Llera. 2010. "The personification of a prophet: leadership, charisma and the globalization of the Angolan Tokoist church". In: Sandra Fancello \& André Mary (eds.), Chrétiens africains en Europe. Paris: Karthala. pp. 69-92.

CAMPOS, Roberta Bivar Carneiro. 2011a. "The prophet, the word and the circulation of Pentecostal charisma". SISR-ISSR, Religion and Economy in a Global World 2011, Aix-en-Provence. Mimeo.

- 2011b. "O profeta, a palavra e a circulação do carisma pentecostal". Revista de Antropologia, 54(2):10131049.

COLEMAN, Simon. 2000. The globalization of Charismatic Christianity: spreading the gospel of prosperity. Cambridge: Cambridge University Press.

. 2001. "Revelations upon Revelation: after shocks, afterthoughts". Interventions, 3(1):100-126.

. 2006. "Materializing the self: words and gifts in the construction of charismatic Christianity identity". In: Fenella Cannell (ed.), The anthropology of Christianity. London: Duke University Press. pp. 163-184.

.2009. "Transgressing the self: making charismatic saints". Critical Inquiry: faith without borders, the curious category of the saint, 35(3):417-439.
COMAROFF, Jean \& COMAROFF, John L. 1991. Of revelation and revolution: Christianity, colonialism, and consciousness in South Africa. vol. 1. Chicago: University of Chicago Press.

COSSU, Andrea. 2010. "Durkheim's argument on ritual, commemoration and aesthetic life: a classical legacy performance theory?" Journal of Classical Sociology, 10(1):33-49.

CRAPANZANO, Vincent. 2000. Serving the word: literalism in America from the pulpit to the bench. New York: The New Press.

CSORDAS, Thomas J. 1997. "Toward a rhetorical theory of charisma". In: Language, charisma and creativity: the ritual life of a religious movement. Berkeley, Los Angeles: University of California Press. pp. 133-155. . 2009. "Introduction: modalities of transnational transcendence". In: Transnational transcendence. Berkeley, Los Angeles: University of California Press. pp. 1-29.

D'EPINAY, Charles L. 1970. O refúgio das massas: estudo sociológico do protestantismo chileno. Rio de Janeiro: Paz e Terra.

ENGELKE, Mathew. 2007. A problem of presence, beyond scripture in an African church. Berkeley, Los Angeles, London: University of California Press.

HARDING, S. F. 2000. The book of Jerry Falwell. Pricenton, Oxford: Princenton University Press.

JERKINS, Philip. 2007. The next christendom: the coming of global Christianity. Oxford: Oxford University Press.

KEANNE, Web. 1993. Christian moderns: freedom and fetish in the mission encounter. Berkeley: University of California Press. 
MARIANO, Ricardo. 2005. Neopentecostais: sociologia do novo pentecostalismo no Brasil. $2^{\mathrm{a}}$ ed. São Paulo: Edições Loyola.

MARTIN, David. 1990. Tongues of fire: the explosion of protestantism in Latin America. Cambridge: Basil Blackwell.

MAURICIO JUNIOR, Cleonardo. 2010. "O carisma e os líderes pentecostais brasileiros: entre o virtuosismo e o capital religioso, da dominação à performance" In: Anais do I Seminário Epistemológico dos Estudos da Religião. pp. 125-133.

. 2011. "Da cultura pentecostal ao líder carismático: os crentes da Assembleia de Deus e a performance do pastor Silas Malafaia". Trabalho de Conclusão de Curso de Graduação em Ciências Sociais, Departamento de Ciências Sociais, Universidade Federal de Pernambuco, Recife. Mimeo.

MOTTA, Roberto M. C. 1991. Edjé Balé. Tese de Concurso para Professor Titular no Depto. de Ciências Sociais do Centro de Filosofia e Ciências Humanas - UFPE, Recife. Mimeo.

ORO, Ari Pedro. 2009. "Transnacionalização religiosa no Cone Sul: uma comparação entre pentecostais e afro-religiosos". Debates do NER, 16:225-245.

. 2010. "'Reciben lo que veniran a buscar': nação e poder num encontro evangélico internacional, em Buenos Aires". Religião e Sociedade, 30(1):32-52.

REINHARDT, Bruno. 2012. "Capturando a unção: mimese, pedagogia e conectividade global em uma escola bíblica Ganense". Trabalho apresentado na $28^{a}$ RBA, São Paulo, $1^{\circ}$ a 5 de julho. Mimeo.

ROBBINS, Joel. 2004. "The globalization of pentecostal and charismatic Christianity". Annual Review of Anthropology, 33:117-143
_ 2008. "Sobre a alteridade e o sagrado em uma época de globalização: O "trans" em "transnacional" é o mesmo "trans" de "transcendente"?". Mana. Estudos de Antropologia Social, 14(1):119-139.

. 2009. "Pentecostal networks and the spirit of globalization: on the social productivity of ritual forms". Social Analysis, 53(1):55-66.

SANCHIS, Pierre 2003. "A contribuição de Émile Durkheim". In: Faustino Teixeira (org.), Sociologia da religião. Petrópolis: Editora Vozes. pp. 33-66.

SEGUY, Jean 1982. "Charisme, sacerdote, fondation: autour de L. M. Grignion de Monfort". Social Compass, XXIX/1:5-24.

STOLL, David. 1982. Fishers of men or founders of empire?: the Wycliffe Bible translators in Latin America. London, Cambridge: Zed Press.

WILLEMS, Emilio. 1967. Followers of the New Faith: culture change and the rise of protestantism in Brazil and Chile. Nashville: Vanderbilt University Press. 


\section{Resumo}

Este artigo tem como objetivo levantar novos aspectos para o entendimento da expansão pentecostal ao focar nas interações entre líderes carismáticos e fiéis comuns, mais especificamente nas práticas e nos significados resultantes destas. Entenderemos como os líderes pentecostais são elevados a uma posição de superioridade espiritual em relação aos crentes ordinários numa religião em que tal diferença hierárquica é contestada. O conceito de carisma e o seu compartilhamento nas referidas interações são categorias indispensáveis à consecução de nosso objetivo. Também estabeleceremos uma relação entre o compartilhamento do carisma e a expansão pentecostal, já que, como veremos, o sucesso pentecostal depende da capacidade que o líder tem de fazer o carisma circular. Tais fatores serão verificados numa comparação entre as performances dos pastores Silas Malafaia e Valdemiro Santiago, as maiores celebridades evangélicas da atualidade, com base em trabalho de campo realizado tanto nas igrejas quanto em eventos capitaneados pelos referidos líderes.

Palavras-chave Líderes carismáticos, Compartilhamento do carisma, Expansão pentecostal.

\section{Abstract}

This article aims to raise new issues in the understanding of Pentecostal expansion by focusing on the interactions between charismatic leaders and ordinary believers, more specifically on the practices and meanings resulting from these interactions. We will investigate how the Pentecostal leaders are elevated to a position of spiritual superiority over the ordinary believers in a religion where such a hierarchy of difference is challenged. The concept of charisma, shared within these interaction, is central to our goal. We will then establish a relationship between the sharing of charisma and pentecostal expansion, since the success of Pentecostalism depends on the ability of the leader has to make charisma circulate. These factors will be verified in a comparison between the performances of the pastors Silas Malafaia and Valdemiro Santiago, the major evangelical celebrities of the day. This work is based on fieldwork carried out both in the churches and in events captained by those leaders.

Key words Charismatic leaders, Sharing of charisma, Pentecostal expansion. 